\title{
The novel anticancer agent JNJ-26854165 is active in chronic myeloid leukemic cells with unmutated BCR/ABL and T315I mutant BCR/ABL through promoting proteosomal degradation of BCR/ABL proteins
}

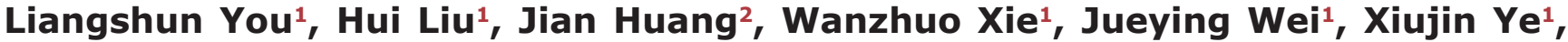 \\ Wenbin Qian ${ }^{1}$ \\ ${ }^{1}$ Institute of Hematology, The First Affiliated Hospital, College of Medicine, Zhejiang University, Hangzhou 310003, P.R. China \\ ${ }^{2}$ Department of Hematology, The Fourth Affiliated Hospital, College of Medicine, Zhejiang University, Yiwu 322000, P.R. China
}

Correspondence to: Wenbin Qian, email: qianwenb@hotmail.com

Keywords: $B C R / A B L, T 315 I$ mutation, chronic myeloid leukemia, JNJ-26854165

Received: May 14, 2016 Accepted: December 05, $2016 \quad$ Published: December 15, 2016

\section{ABSTRACT}

Chronic myeloid leukemia (CML) is a clonal malignant disease caused by the expression of BCR/ABL. MDM2 (human homolog of the murine double minute-2) inhibitors such as Nutlin-3 have been shown to induce apoptosis in a p53-dependent manner in CML cells and sensitize cells to Imatinib. Here, we demonstrate that JNJ-26854165, an inhibitor of MDM2, inhibits proliferation and triggers cell death in a p53-independent manner in various BCR/ABL-expressing cells, which include primary leukemic cells from patients with $\mathrm{CML}$ blast crisis and cells expressing the Imatinibresistant T315I BCR/ABL mutant. The response to JNJ-26854165 is associated with the downregulation of $B C R / A B L$ dependently of proteosome activation. Moreover, in all tested CML cells, with the exception of T315I mutation cells, combining JNJ-26854165 and tyrosine kinase inhibitor (TKI) Imatinib or PD180970 leads to a synergistic effect. In conclusion, our results suggest that JNJ-26854165, used either alone or in combination with TKIs, represents a promising novel targeted approach to overcome TKI resistance and improve patient outcome in CML.

\section{INTRODUCTION}

Chronic myeloid leukemia (CML) is a clonal malignant disease hallmarked by the expression of the $\mathrm{BCR} / \mathrm{ABL}$ fusion protein that results from a reciprocal translocation involving chromosomes 9 and 22. BCR/ $\mathrm{ABL}$ possesses a deregulated tyrosine kinase activity that drives a number of downstream signaling pathways, confers survival and proliferation advantages and restrains apoptosis, thus contributing to the pathogenesis of CML [1]. Imatinib mesylate, a small molecule tyrosine kinase inhibitor (TKI) that competitively binds to the ATP-binding site of $\mathrm{BCR} / \mathrm{ABL}$, is currently considered a first-line agent for the treatment of patients with newly diagnosed chronic-phase (CP) CML [2, 4]. Imatinib induces durable cytogenetic and molecular remission and prolonged lifespan in the majority of patients with CML [5], but approximately $20-30 \%$ of the patients eventually experience drug resistance, mainly as a consequence of mutations in the $\mathrm{BCR} / \mathrm{ABL}$ kinase domain, genomic amplification of nonmutated $\mathrm{BCR} / \mathrm{ABL}$ and $\mathrm{BCR} / \mathrm{ABL}$ independence pathway [5-8]. The second-generation TKIs nilotinib, dasatinb, and bosutinib target most Imatinibresistant $\mathrm{BCR} / \mathrm{ABL}$ mutants. However, none of them is effective in patients with the T315I mutation [9]. In addition, all agents aimed at targeting the ATP-binding pocket of the BCR/ABL kinase domain alone do not eliminate CML stem cells [10-12].

The p53 tumor suppressor provides a potent barrier to cancerigenesis by inducing cell-cycle checkpoints, cellular senescence, or apoptosis in response to DNA damage and aberrant proliferative signals [13]. p53 mutations occur in approximately $50 \%$ of all cancers [14]. In human CML almost no p53 mutations is found, but in the blast-crisis phase (BC) and accelerated phase (AP) of CML more than $20 \%$ of patients display mutated p53 $[15,16]$. Moreover, the function of wild-type (wt) p53 in CML can be disrupted by a sustained expression of MDM2, the crucial negative p53 regulator [17]. In vitro studies have shown that induction of p53 through MDM2 
inhibition by the small-molecules such as Nutlins and MI219 effectively induces p53-mediated apoptosis in most blast crisis CML cells, with or without mutations including T315I variant [18, 19].

JNJ-26854165 (JNJ-165) is a novel small molecule that was initially thought to act as an antagonist to MDM2. [20, 21]. In a phase I trial performed in patients with refractory solid tumors, JNJ-165 displayed a modest anticancer activity and enabled p53 activation in vivo [22]. However, recent pre-clinical studies have demonstrated antiproliferative activity in various p53 wt and mutant cancer models [20, 23, 24], implying p53-independent activities. Thus, these two properties provide an advantage to prevent the selection of p53 mutant subclone in cancer during treatment of JNJ-165.

The aims of this study were to evaluate the efficacy of JNJ-165 in CML cells with or without p53 mutation in vitro and in vivo as a single agent and in combination with TKI and to confirm the mechanism of action of this potentially important drug in CML cells.

\section{RESULTS}

\section{Antiproliferative and apoptotic effects of JNJ-165 in models of Imatinib-sensitive and-resistant CML}

We first examined the antiproliferation effect of JNJ-165 on primary cells from 24 newly diagnosed patients with CML, 9 patients with CML-AP/BC, and 13 cases with CML-CP treated with Imatinib or dasatinib, in whom expression of $\mathrm{BCR} / \mathrm{ABL}$ mRNA determined by real time RT-PCR was very low or undetectable. The characteristics of the $46 \mathrm{CML}$ patients analyzed in this study are detailed in Supplementary Table S1. CML primary cells were exposed to $2 \mu \mathrm{M}$ JNJ-165 for 72 hours, the viability of cells from the CML-CP patients with $\mathrm{BCR} / \mathrm{ABL}$ positive and CML AP/BP patients was reduced by $32.9 \%$ and $23.4 \%$, respectively, compared with cells from the patients with very low or undetectable BCR/ABL (Figure 1A). We next evaluate the cytotoxicity of JNJ-165 to normal hematopoietic progenitor cells by colony formation assays. The results presented in Supplementary Figure S1 revealed that the number of hematopoietic colonies were not affected by JNJ-165. To investigate the effect of JNJ-165 on growth of CML cell lines, K562 and $\mathrm{K} 562 / \mathrm{G}$, an Imatinib-resistant cell line were incubated for 72 hours with escalating concentrations of JNJ-165. Cell viability of both cell types was inhibited with $\mathrm{IC}_{50}$ values of 1.54 and $1.67 \mu \mathrm{M}$, respectively (Figure 1B), suggesting similar sensitivity of these two cell lines to JNJ-165. Next, we treated a pair of murine 32D leukemic cell lines stably expressing wt or T315I mutant BCR/ABL (32D-BCR/ABL and 32D- BCR/ABL- T315I) with JNJ-165 and observed their growth remarkably inhibited, with $\mathrm{IC}_{50}$ values of 0.46 and $0.5 \mu \mathrm{M}$, respectively (Figure 1B). These data indicate that JNJ-165 is a potential agent to kill Imatinib-sensitive and resistant CML cells including cells with the T315I mutation.

To further clarify whether the antiproliferative activity of JNJ-165 was related to induction of apoptosis, Annexin V-FITC and PI double staining was performed. Treatment of $\mathrm{K} 562$ and $\mathrm{K} 562 / \mathrm{G}$ cells with $2 \mu \mathrm{M}$ JNJ-165 for 48 hours resulted in $15.6 \%$ and $22.9 \%$ apoptotic (annexin $\mathrm{V}^{+}$and $\mathrm{PI}^{+}$) cells, respectively (Figure 1C). This is consistent with a previous report showing that JNJ-165 induced delayed apoptosis in p53 mutant cells including K562 cells [20]. However, JNJ-165 cytotoxicity against K562 and 32D-BCR/ABL-T315I cells was not significantly reduced by z-VAD-fmk pretreatment (Figure 1D), suggesting that cell death was caspaseindependent.

\section{JNJ-165-induced cell death is p53-independent}

Since all CML cell lines used in this study had mutant-type p53 and JNJ-165 has been demonstrated to increase MDM2 and p53 levels in leukemia cells with wt p53 [20], we examined whether JNJ-165 affected this pathway in K562 cells. A small amount of p53 was diffusely distributed in the cytoplasm of untreated cells. After a 48-hour treatment with $2 \mu \mathrm{M}$ JNJ-165, cells showed nuclear accumulation of p53 (Figure 2A). By examining intracellular distribution of MDM2 and p53 using Western blot analysis, we found that MDM2 protein and phospho-MDM2 (Ser166) were increased in the cytoplasm in a dose-dependent manner during JNJ-165 treatment, but not in the nucleus. In contrast, increased level of phospho-p53 was only observed in the nuclear fraction of cells treated with this agent (Figure 2B).

It was reported that pifithrin- $\alpha(\mathrm{PFT} \alpha)$, a chemical inhibitor of p53, reversibly blocks p53-transcriptional activity, preventing p53-mediated apoptosis [25]. In order to evaluate the possible role of p53 in the cytotoxicity of JNJ-165, we examined effect of PFT $\alpha$ on JNJ-165-induced cell growth inhibition. Pretreatment with PFT $\alpha$ for 3 hours followed by addition of JNJ-165 in K562 cells did not result in a significant reduction in cell death compared with JNJ-165 alone (Figure 2C). In view of these results, we further examined the inhibitory activity of Nutlin-3, a small-molecule antagonist of MDM2 that inhibits MDM2-mediated degradation of p53 [18, 26], against K562 and K562G cell lines. Although treatment with Nutlin-3 induced cell growth inhibition in these cells, $\mathrm{IC}_{50}$ values for K562 and K562G were 12.87 and $11.21 \mu \mathrm{M}$, respectively (Supplementary Figure S2). Taken together, these data suggest that killing of all tested CML cell lines with mutant p53 by JNJ-165 is bypass of p53 pathway. 


\section{JNJ-165 depletes wt and mutant BCR/ABL and inactivates its downstream signaling}

Next, we investigated the effect of JNJ-165 on the expression of BCR/ABL in CML cells by immunoblotting. Treatment with JNJ-165 for 48 hours resulted in not only decreased level of wt BCR/ABL in K562, K562G and 32D-BCR/ABL cells (Figure $3 \mathrm{~A}$ and $3 \mathrm{~B}$ ) but also downregulation of T315I mutation $\mathrm{BCR} / \mathrm{ABL}$ in 32D-BCR/ABL -T315I cells, in a dose-dependent manner (Figure 3B). To determine if the inhibition of total $\mathrm{BCR} / \mathrm{ABL}$ protein leads to a decrease in its kinase activity, we evaluate the ability of JNJ-165 to inhibit the phosphorylation of $\mathrm{BCR} / \mathrm{ABL}$ and its downstream targets CrkL and STAT3/5, which have been implicated in transformation and antiapoptotic signaling stemming from constitutive activation of the BCR/ABL kinase $[27,28]$. Immunoblotting analyses showed that treatment of $\mathrm{K} 562, \mathrm{~K} 562 \mathrm{G}, 32 \mathrm{D}-\mathrm{BCR} / \mathrm{ABL}$ or $32 \mathrm{D}-\mathrm{BCR} /$ ABL-T315I cells with JNJ-165 resulted in a potent decrease in the phosphorylated levels of BCR/ABL in accord with decrease in the total $\mathrm{BCR} / \mathrm{ABL}$ protein (Figure $3 \mathrm{~A}$ and $3 \mathrm{~B}$ ). Furthermore, at concentrations that correlated with its cytotoxic effects, JNJ-165 effectively inhibited the phosphorylation of STAT5 and STAT3. Phosphorylation of the $\mathrm{BCR} / \mathrm{ABL}$ substrate CrkL was

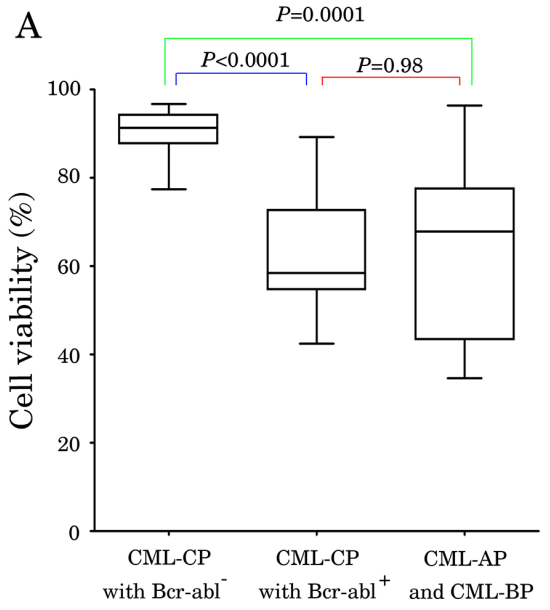

C

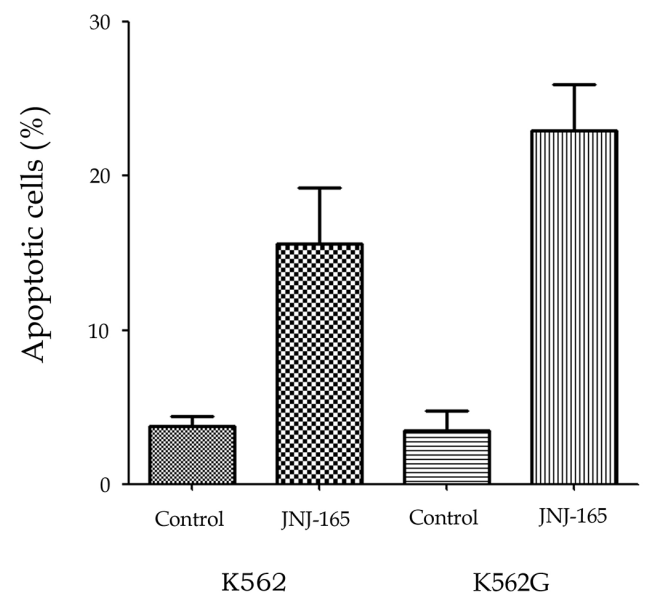

B

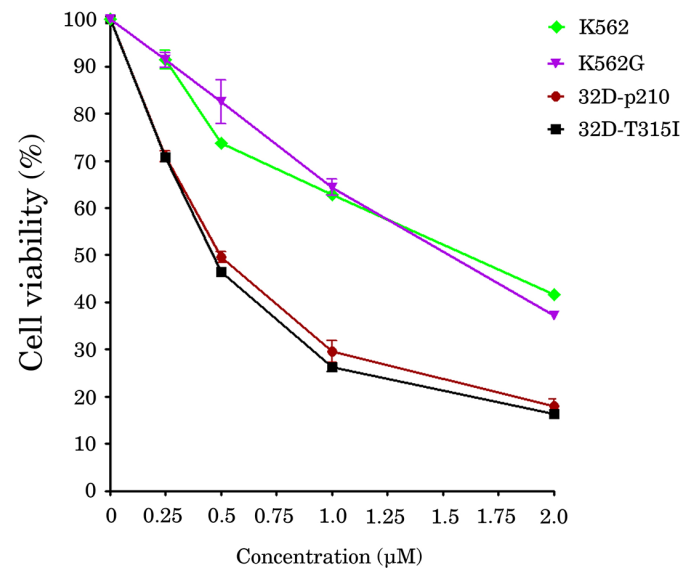

D

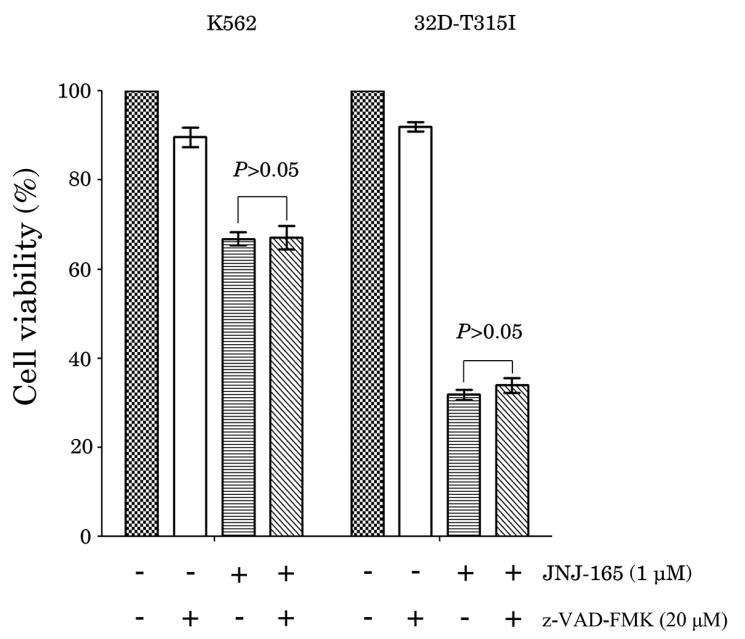

Figure 1: JNJ-165 inhibits proliferation and induces death in CML cell lines and primary cells (Imatinib-sensitive and -resistant) via caspase-independent pathway. (A) The primary cells were obtained from CML patients, and were cultured with or without $2 \mu \mathrm{M} \mathrm{JNJ}-165$ for $72 \mathrm{~h}$, the viability of cells was assessed by an MTT assay. (B) CML cell lines K562, K562/G, 32D-BCR/ABL, and 32D-BCR/ABL-T315I, were cultured with or without different concentrations of JNJ-165 for $72 \mathrm{~h}$. Growth inhibition by JNJ-165 was assessed by an MTT assay. Data were represented mean \pm SD of three independent experiments. (C) CML Cell lines K562 and K562/G were harvested at $48 \mathrm{~h}$ after treatment with $2 \mu \mathrm{M} \mathrm{JNJ}-165$. Cells were stained by an annexin V/PI-staining method and analyzed by flow cytometry. (D) Cell lines K562 and 32D-BCR/ABL-T315I were incubated for $6 \mathrm{~h}$ with $20 \mu \mathrm{M}$ z-VAD-fmk, then exposed to $1 \mu \mathrm{M}$ JNJ-165 for $72 \mathrm{~h}$, the viability of cells was assessed by an MTT assay. Results are representative of three independent experiments and expressed as the mean $\pm \mathrm{SD}$. 
also downregulated, although to a lesser extent, in K562 and K562G cell lines (Figure 3A). Importantly, JNJ-165 $(2 \mu \mathrm{M})$ was shown to significantly inhibit the phosphorylation of BCR/ABL and lower STAT5 and STAT3 kinase activity in both primary CML cells and primary CML cells harboring E255K, an Imatinib-resistant mutation [29, 30] (Figure 3C). Conversely to JNJ-165, PD180970, an inhibitor of protein tyrosine kinases against several imatinib-resistant mutations [31, 32], slightly decreased the amount of phosphorylated BCR/ABL and its downstream targets.

\section{JNJ-165 promotes the proteasomal degradation and reduces the mRNA of $B C R / A B L$}

Attempts were then made to determine whether JNJ-165-mediated inhibition of BCR/ABL is because of repression of the BCR/ABL mRNA. K562 and K562G cells were exposed to varying concentration of JNJ-165 for 48 hours; real-time RT-qPCR analyses revealed that the mRNA transcripts of BCR/ABL were decreased in a dose-dependent fashion (Figure 3D). By using a luciferase reporter assay system, we studied the effect of JNJ-165 on the activity of the BCR promoter. Surprisingly, JNJ165 did not induce significantly decreased transactivation of this promoter and that of AFP promoter (an unrelated gene control) (Figure 3E). Whether protein degradation through 26S proteasome contributes to JNJ-165-mediated decrease in the levels of $\mathrm{BCR} / \mathrm{ABL}$ is not yet clear. To investigate this, we examined the effect of treatment with
$2 \mu \mathrm{M}$ JNJ-165 with or without the proteasome inhibitor MG-132 $(0.5 \mu \mathrm{M})$ for 48 hours on the protein level of $\mathrm{BCR} / \mathrm{ABL}$ in $\mathrm{K} 562$ and $\mathrm{K} 562 \mathrm{G}$ cells. MG-132 could reverse the inhibition of BCR/ABL by JNJ-165 markedly (Figure 4A). Consistent with these results, apoptosis induced by JNJ-165 can be rescued partially by MG-132 (Figure 4C). As C-Abl is a substrate of caspase-3 [33], we checked the effect of caspase-3 inhibitor (z-DEVD-fmk) on JNJ-165-mediated downregulation of BCR/ABL, but found that $\mathrm{z}$-DEVD-fmk did not restore the decline in BCR/ABL levels, excluding the possibility that JNJ-165induced $\mathrm{BCR} / \mathrm{ABL}$ decrease was dependent of caspase-3 activation. On the other hand, cotreatment of CML cells with JNJ-165 and the protein synthesis inhibitor cycloheximide (CHX) depleted the levels of BCR/ABL. Similar results were obtained with the $32 \mathrm{D}-\mathrm{BCR} / \mathrm{ABL}$ and 32D-BCR/ABL-T315I cells (Figure 4B).

The tumor suppressor phosphatase 2A (PP2A) is known to activate protein tyrosine phosphatase 1 (SHP-1), which catalyzes $\mathrm{BCR} / \mathrm{ABL}$ dephosphorylation and proteosomal degradation $[34,35]$. We, therefore, examined whether PP2A is regulated by JNJ-165 treatment. As shown in Figure 4D, JNJ-165 induced increased expression of PP2A in K562 and 32D-BCR/ABL-T315I cells in a dose-dependent fashion, which coincided with the upregulation of SHP-1. To determine whether the downregulation of Bcr-abl protein after JNJ-165 treatment was linked to its ubiquitination, protein lysates from JNJ165-treated cells were immunoprecipitated with anti-c$\mathrm{Abl}$ antibody and then followed by immunoblotting with
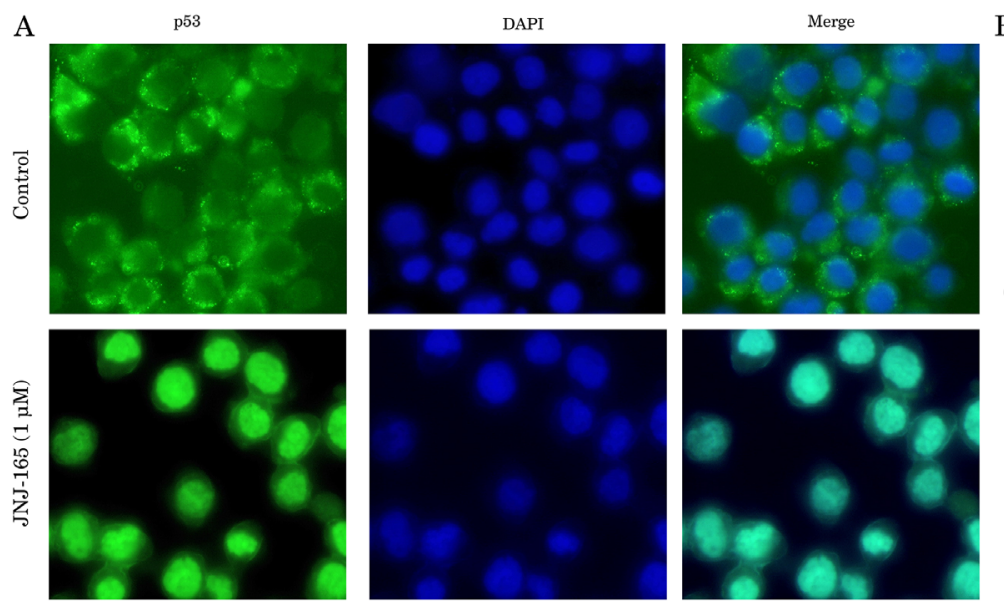

B
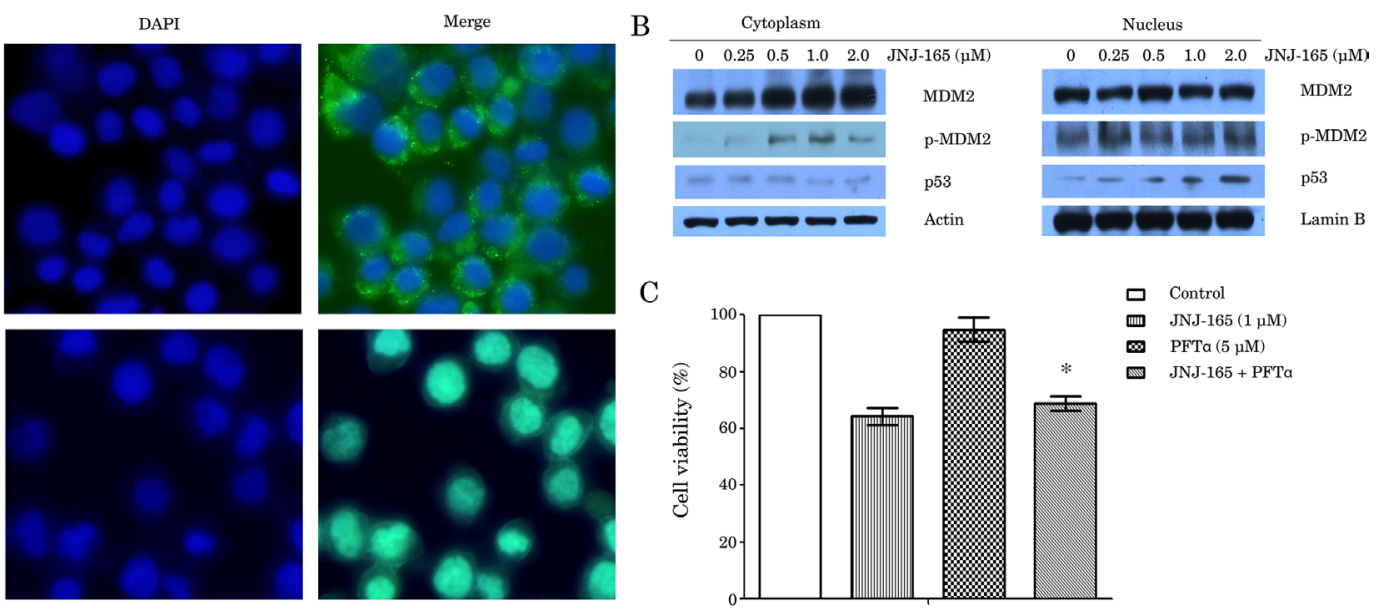

Figure 2: JNJ-165-induced CML cell lines death is p53-independent. (A) Two-color fluorescence microscope analysis of antibody against p53 protein (green) and nuclei (DAPI staining, blue) showed nuclear accumulation of p53 in K562 cells with treatment of $1 \mu \mathrm{M}$ JNJ-165, but not in control-treated cells after $48 \mathrm{~h}$. Images were taken on a fluorescence microscopy (100×). (B) K562 cells was harvested at $48 \mathrm{~h}$ after treatment with various JNJ-165 concentrations, and then nuclear and cytoplasmic extracts were prepared to check the levels of p53, MDM2 and p-MDM2 by Western blotting. Actin and LaminB were used as loading control respectively. (C) Cell viability was assessed by MTT assay after pretreatment with $5 \mu \mathrm{M}$ PFT $\alpha$ for $3 \mathrm{~h}$ followed by addition of $1 \mu \mathrm{M}$ JNJ-165 in K562 cells. Combined treatment group did not display a significant reduction in cell death compared with JNJ-165 alone. Data are expressed as the mean \pm SD of three independent experiments, and analyzed by ANOVA followed by the Tukey $t$ test. $* P>0.05$. 
anti-ubiquitin antibody. Results showed that JNJ-165 treatment of K562 cells led to a marked accumulation of polyubiquitinated c-Abl (Figure 4E). Collectively, these data indicate that JNJ-165 may trigger BCR/ABL degradation by the proteasome via PP2A-dependent mechanisms.

\section{Synergistic activity of JNJ-165 with TKIs Imatinib or PD180970}

The combination of JNJ-165 and Imatinib or PD180970 was assessed by the MTT assay in K562, K562G, 32D-BCR/ABL, and 32D-BCR/ABL-T315I cell

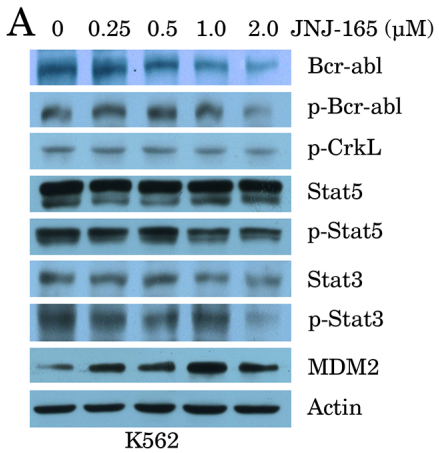

$\begin{array}{llllll}0 & 0.25 & 0.5 & 1.0 & 2.0 & \mathrm{JNJ}-165 \\ (\mu \mathrm{M})\end{array}$

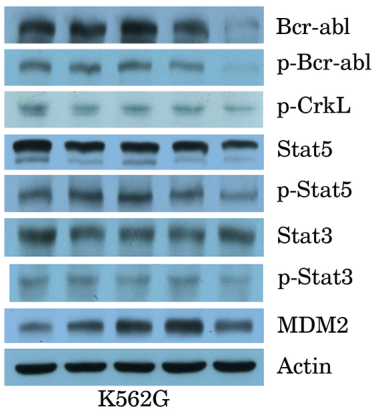

B

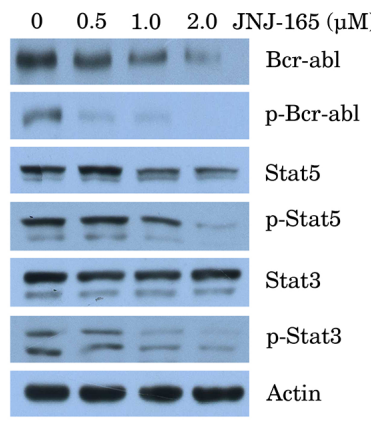

32D-p210

$\mathrm{D}$

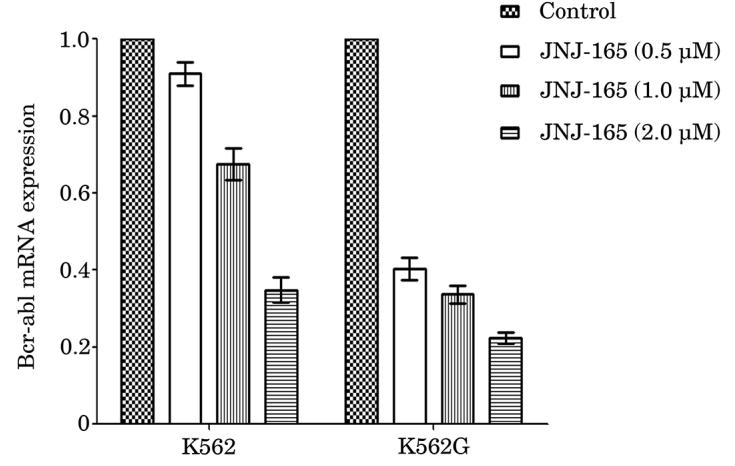

C

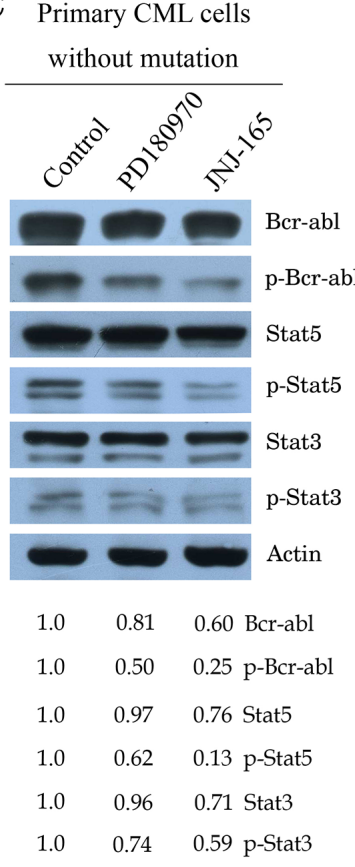

$\mathrm{E}$

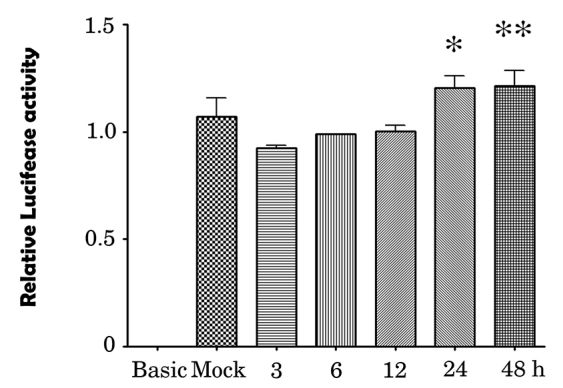

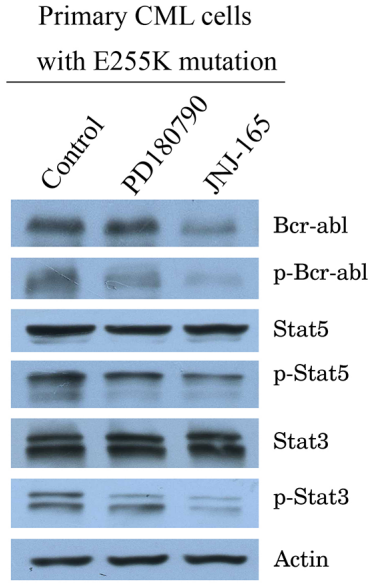

$1.0 \quad 0.96 \quad 0.60$ Bcr-abl

$\begin{array}{lll}1.0 & 0.64 & 0.37 \text { p-Bcr-abl }\end{array}$

$\begin{array}{lll}1.0 & 0.73 \quad 0.81 \text { Stat5 }\end{array}$

$1.0 \quad 0.69 \quad 0.57$ p-Stat5

$1.0 \quad 0.94 \quad 0.94$ Stat3

$\begin{array}{lll}1.0 & 0.73 \quad 0.24 \mathrm{p} \text {-Stat3 }\end{array}$

Figure 3: Investigations on the effect of JNJ-165 on promoter activity, mRNA level and protein expression of BCR-ABL. (A) and (B) Four kinds of CML cell lines were treated with JNJ-165 at the indicated doses for $48 \mathrm{~h}$. Whole-cell lysates were extracted to assess the levels of BCR-ABL and phosphorylated (p)-BCR-ABL (Tyr177), and then were analyzed for BCR-ABL downstream signaling mediators p-CrkL (Try207), total Stat5, p-Stat5 (Tyr694), total Stat3, and p-Stat3 (Ser727) expression by Western blot analysis. The expression of $\beta$-actin was used as loading control. The data are representative of three determinations with identical results. (C) The primary leukemic cells from a newly diagnosed CML patient without mutation and a primary CML patient harboring E255K mutation were treated with PD180970 $(50 \mathrm{nM})$ or JNJ-165 $(2 \mu \mathrm{M})$, and then protein expression was determined using Western blotting. JNJ-165 significantly inactivates $\mathrm{p}-\mathrm{BCR} / \mathrm{ABL}$ (wt/mutation) and its downstream signaling mediators. The difference in the levels of protein expression was semiquantitatively determined by densitometry and expressed as a ratio. Actin was used as loading control. (D) RT-qPCR analysis monitoring $\mathrm{BCR} / \mathrm{ABL}$ mRNA expression in K562 and K562G cells that were exposed to varying concentration of JNJ-165 for $48 \mathrm{~h}$. Bars represent SD. of three independent experiments. (E) 293T cells were transfected with BCR promoter-luciferase report plasmid for $24 \mathrm{~h}$, and then treated with $2 \mu \mathrm{M} J \mathrm{NJ}-165$ for the indicated times. Cell lysates were analyzed for luciferase activity using the Luciferase Assay System Kit (Promega). Standard error was calculated from three independent experiments. ${ }^{*} P>0.05,24 \mathrm{~h}$ vs control; ** $P>0.05,48 \mathrm{~h}$ vs control. 
lines. First, K562 and Imatinib-resistant K562G cells were treated with a series of doses of JNJ-165 and PD180970 for 48 hours, and combination index (CI) was calculated by Chou and Talalay's method. A synergism was confirmed in both of these cell lines (Figure 5A and 5B). Similar result was also obtained with the cell lines treated with JNJ-165 in combination with Imatinib (Figure 5C). In 32D cells expressing wt BCR/ABL, all combinations of JNJ165 with the TKIs significantly reduced cell proliferation compared with either agent alone (Figure 5D). However, in 32D cells harboring T315I mutation the cotreatment with JNJ-165 and either TKI did not result in a significant reduction in cell proliferation compared with JNJ-165 alone, while the imatinib or PD180970 alone treatment failed to inhibit cell growth (Figure 5D). This supports the view that CML cells containing T315I are resistant to both imatinib and PD180970 [6, 32].

The interactions between JNJ-165 and PD180970 were then examined in relation to perturbations in the BCR/ABL signaling pathway. Treatment with JNJ-165 or
PD180970 alone modestly decreased the levels of BCR/ ABL protein and phospho-BCR/ABL, but this effect was enhanced by coadminstration of JNJ-165 and PD180970. Furthermore, level of phospho-STAT5 was significantly decreased in cells exposed to both agents with respect to cells treated with JNJ-165 or PD180970 alone (Figure 5E). Consistent with the significant reduction in the levels of phospho-BCR/ABL and phospho-STAT5, an enhanced apoptosis, evidenced by activation of caspase pathway, was observed in K562 cells exposed to the JNJ-165 and PD180970 combination (Figure 5F).

Next, the impact of combined treatment of CML cell lines with JNJ-165 and Imatinib or PD180970 was determined in relation to effects on clonogenic survival (Figure 5G and 5H). Imatinib (12.5 nM) or PD180970 $(12.5 \mathrm{nM})$ by itself had a slight effect on colony formation, whereas JNJ-165 $(0.5 \mu \mathrm{M})$ administered alone reduced clonogenic survival by $6.25 \%, 23.5 \%$ and $39.3 \%$, respectively in $\mathrm{K} 562$, $\mathrm{K} 562 \mathrm{G}$ and $32 \mathrm{D}-\mathrm{BCR} / \mathrm{ABL}$ cell lines. However, all combinations of JNJ-165 with the

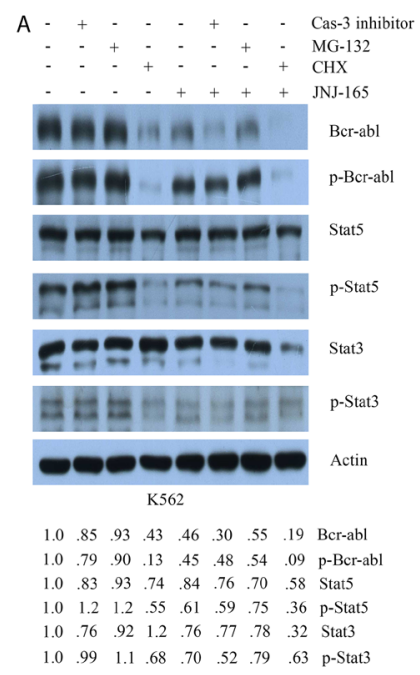

C

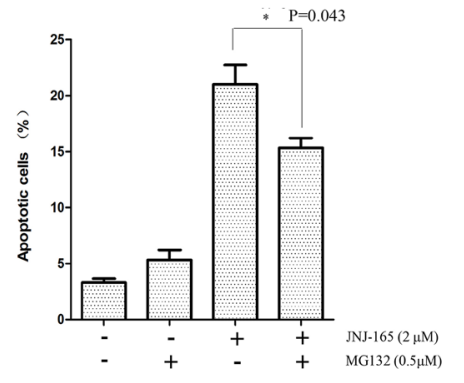

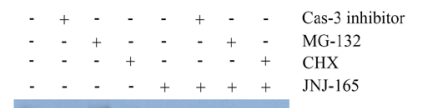
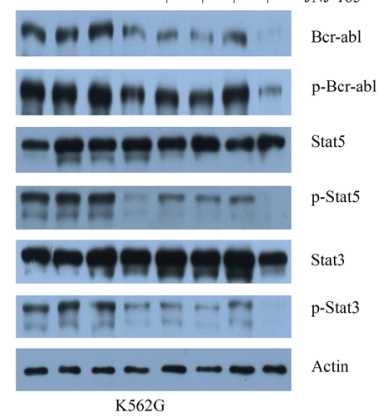

$\begin{array}{lllllllll}1.0 & 1.1 & 1.2 & .71 & .61 & .59 & .80 & .35 & \text { Ber-abl }\end{array}$ $\begin{array}{lllllllll}1.0 & 1.1 & 1.1 & .75 & .80 & .76 & .96 & .29 & \text { p-Bcr-abl }\end{array}$ $\begin{array}{llllllllll}1.0 & 1.4 & 1.3 & 1.3 & 1.2 & 1.3 & 1.2 & 1.1 & \text { Stat } 5\end{array}$ $\begin{array}{llllllllll}1.0 & 1.1 & 1.1 & .41 & .73 & .75 & .73 & .12 & \text { p-Stat5 }\end{array}$ $\begin{array}{llllllllll}1.0 & 1.1 & 1.1 & 1.1 & 1.0 & 1.2 & 99 & .89 & \text { Stat3 }\end{array}$ $\begin{array}{lllllllll}1.0 & 1.2 & 1.1 & .62 & .66 & .58 & .81 & .15 & \text { p-Stat3 }\end{array}$

D

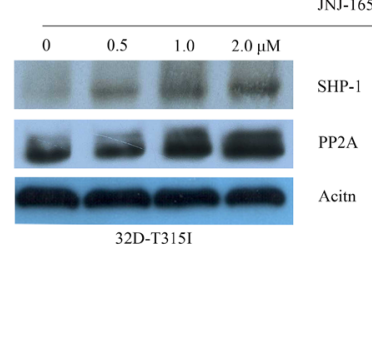

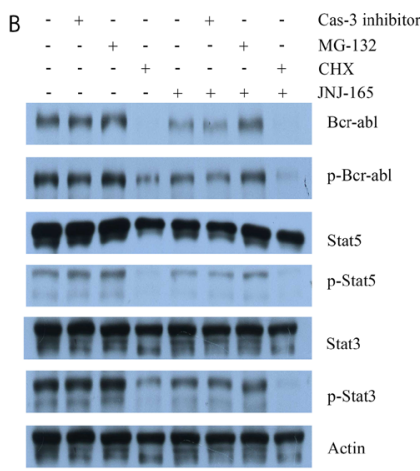

$\begin{array}{lllllllll}1.0 & 98 & 1.1 & .12 & .54 & .51 & 1.0 & .15 & \mathrm{Bcr}-\mathrm{abl}\end{array}$ $\begin{array}{lllllllll}1.0 & .98 & 1.1 & .12 & .54 & .51 & 1.0 & .15 & \text { Bcr-abl } \\ 1.0 & .85 & 1.1 & .56 & .66 & .54 & .86 & .31 & \text { p-Ber-abl }\end{array}$

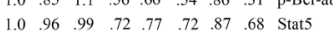
$\begin{array}{llllllllll}1.0 & 1.2 & 1.5 & .30 & .64 & .59 & .92 & .25 & \mathrm{p} \text {-Stat5 }\end{array}$ $\begin{array}{lllllllll}1.0 & 1.1 & .95 & .72 & .84 & .79 & .81 & .73 & \text { Stat3 }\end{array}$ $\begin{array}{llllllllll}1.0 & 1.0 & 1.1 & .47 & .64 & .63 & .77 & .21 & \text { p-Stat3 }\end{array}$

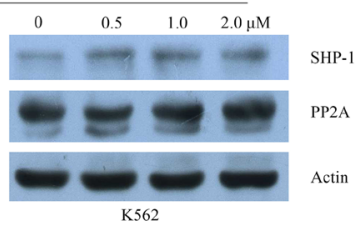

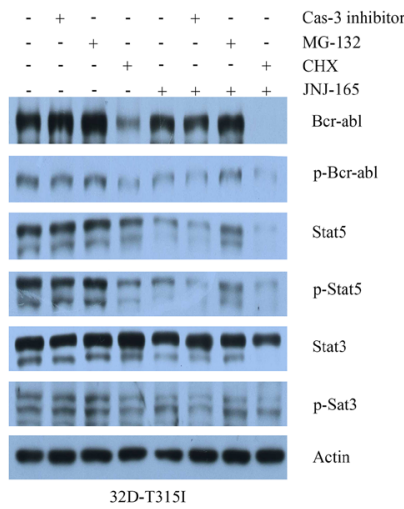

$\begin{array}{lllllllll}1.0 & 1.1 & 1.2 & .42 & .72 & .64 & .96 & .06 & \text { Bcr-abl }\end{array}$ $\begin{array}{lllllllll}1.0 & 85 & 88 & .39 & .41 & .29 & .64 & .20 & \text { p-Bcr-abl }\end{array}$ $\begin{array}{lllllllll}1.0 & 1.0 & 1.0 & .65 & .18 & .21 & .55 & .08 & \text { Stat5 }\end{array}$

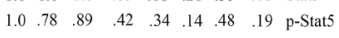
$\begin{array}{llllllllll}1.0 & .94 & 1.1 & 1.2 & .79 & .84 & .77 & .55 & \text { Stat }^{3}\end{array}$ $\begin{array}{lllllllll}1.0 & 1.0 & 1.1 & .80 & .70 & .46 & .74 & .52 & \text { p-Stat3 }\end{array}$

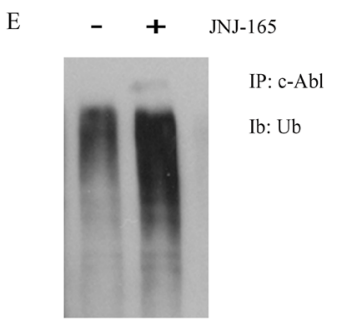

Figure 4: JNJ-165-mediated downregulation of BCR/ABL by promoting the proteosomal degradation pathway via PP2A-dependent mechanisms. (A) and (B) Pretreatment with $2 \mathrm{~h}$ with z-DEVD-fmk $(20 \mu \mathrm{M})$ or MG132 $(0.5 \mu \mathrm{M})$ or CHX (1 $\mu \mathrm{g} / \mathrm{ml})$, then exposed to $2 \mu \mathrm{M} J \mathrm{NJ}-165$ for $48 \mathrm{~h}$, whole cell proteins extracted from four kinds of CML cell lines were quantified and loaded. Western blotting was used to analyze the expression of total BCR/ABL, p-BCR-ABL (Tyr177), total Stat5, p-Stat5 (Tyr694), total Stat3, and p-Stat3 (Ser727). Actin was used as a loading control. The difference in the levels of protein expression was semi-quantitatively determined by densitometry and expressed as a ratio. (C) K562 cells were treated with JNJ-165 alone or combined with MG-132 (0.5 $\mu \mathrm{M})$ for $48 \mathrm{~h}$ and apoptosis was determined by flow cytometry. (D) 32D-BCR/ABL-T315I and K562cells were treated with JNJ-165 at the indicated doses for $48 \mathrm{~h}$ and then analyzed for expression of SHP-1 and PP2A by Western blotting. Actin was used as a loading control. The results are representatives of three separate experiments. (E) Lysates from cells treated with PBS (control) or $2 \mu \mathrm{M}$ JNJ-165 were subjected to immunorecipitations with anti-c-Abl. Immunoprecipitates were washed, resolved on gels, and immunoblotted for ubiquitin. 
TKIs resulted in a substantial reduction in clonogenicity (32.5\% of control values for JNJ-165 plus Imatinib and $6.25 \%$ for JNJ-165 plus PD180970 in K562 cells). A similar synergistic effect was also observed in K562G and 32D-BCR/ABL cells, but not in 32D-BCR/ABL-T315I cells $(P>0.05)$.

Finally, we investigated if the combination of JNJ-165 and a TKI demonstrated a beneficial effect in primary cells from patients with CML. Mononuclear cells derived from bone marrow of patients with CML-CP and CML-AP or BP and from healthy individuals were treated with JNJ-165, Imatinib or PD180970 alone, or with JNJ-165 in combination either TKI for 72 hours, and cell viability was measured. Consistent with data from the cell lines, JNJ-165 and either TKI synergized to inhibit the proliferation of cells expressing $\mathrm{BCR} / \mathrm{ABL}$ from newly diagnosed patients with CML-CP and from patients with CML-AP or BP (Figure 5J). However, the primary cells from CML patients treated with Imatinib or dasatinib, in whom the level of BCR/ABL gene expression was very low or negative, were resistant to JNJ-165, the TKIs, and combination therapy with JNJ-165 and either TKI (Figure 5I). As a control, we observed the number of colony forming units (CFUs) after treatment with JNJ-165, PD180970 or their combination in the primary cells from healthy individuals $(n=4)$ were also resistant to the above treatment (data not shown).

\section{JNJ-165 and TKIs induce synergetic lethality in CML cells, but not in T315I cells in vivo}

We assessed the implications of our findings in vivo by using two different animal models: K562 and 32D-BCR/ABL-T315I xenografts in SCID mice. The growth of tumors established from K562 cells was significantly suppressed in the mice treated with either JNJ-165 or PD180970 as compared with the control mice $(P<0.0001$; Figure 6A). However, combination treatment showed an impressive antitumor activity. The mean tumor volumes of animals treated with JNJ-165 or PD180970 were $3033.2 \mathrm{~mm}^{3}$ and $2932.1 \mathrm{~mm}^{3}$, respectively on day 27 after start of therapy. In marked contrast, the mean tumor volume of animals cotreated with two drugs was $805.4 \mathrm{~mm}^{3}$. Consistent with these results, the combination therapy dramatically prolonged survival compared with each agent alone (Figure 6B; $P=0.0269$ ). Furthermore, the levels of $\mathrm{BCR} / \mathrm{ABL}$ protein, phospho-BCR/ABL and downstream molecules were significantly lower in co-treated tumor than in tumors treated with JNJ-165 or PD180970 (Figure 6C), which may contribute to combination therapy cytotoxicity.

It is important to note that neither PD180970 nor Imatinib were growth inhibitory to the $32 \mathrm{D}-\mathrm{BCR} / \mathrm{ABL}-$ T315I tumors (Figure 6D) and prolonged the survival of mice (Figure 6E). In contrast, JNJ-165 alone caused an almost complete regression of tumors established from
32D-BCR/ABL-T315I cells and significantly prolonged the survival compared with untreated control $(P=0.0015)$. All control mice died within 21 days, while all mice treated with PD180970 or Imatinib died before day 22. Whereas, only two out of five mice $(40 \%)$ receiving JNJ-165 died within 25 days because of gastrointestinal toxicity such as asthenia and anorexia (Figure 6E). As expected, significant downregulation of BCR/ABL and downstream molecules was observed in the section from JNJ-165treated animal, but not in tumors from mice treated with PD180970 or Imatinib (Figure 6F). Additionally, there were no synergetic effects of JNJ-165 and PD180970 on tumor growth and animal survival. Taken together, these data indicated that a critical role of JNJ-165 is required in order to achieve a therapeutic effect.

\section{DISCUSSION}

Although TKIs has revolutionized drug therapy of CML, the development of drug resistance and persistence of TKI-insensitive leukemic stem cells remain obstacles to eradicating the disease. The MDM2 has become a validated target for cancer treatment because of its important role in negative regulation of p53 [36]. A number of recent studies have reported that small molecular inhibitors of MDM2 induce apoptosis in BCR/ABL expressing cells, including CML blast crisis cells regardless of the presence of the T315I mutation $[18,19]$. JNJ-165 is a novel tryptamine derivative with $\mathrm{p} 53$-activating properties reported act as a MDM2 inhibitor with in vitro or in vivo efficacy in acute leukemia, lymphoma, and solid tumors [20, 22, 24]. In this study, we have evaluated JNJ-165 in a variety of CML cell lines with p53 mutation, including those resistant to Imatinib and harboring T315I mutation, and primary CML cells, most of them being wild type p53 $[15,16]$. We found that, unlike the selective MDM2 antagonist Nutlin-3 that was not active in $\mathrm{K} 562$ and $\mathrm{K} 562 \mathrm{G}$ cells, JNJ-165 showed a strong activity against all tested cell lines containing mutation p53 and primary CML cells. JNJ-165 also significantly inhibited the growth of Imatinib-resistant BCR/ABL-T315I as well as Imatinib-sensitive CML cells in mouse xenografts. Although some p53 induction was observed in K562 cells treated with JNJ-165, PFT $\alpha$, an inhibitor of p53, did not prevent JNJ-165-mediated cell death, suggesting that cell death induced by JNJ-165 is independent of the MDM2-p53 interaction in human CML cells. The most notable effect on cells was an inhibition of BCR/ABL in both cells bearing wild-type BCR/ABL and T315I mutant BCR/ABL. Taken together, these data suggest that JNJ-165 could be a useful therapeutic agent in CML.

Recently, some studies have suggested that promoting the degradation of $\mathrm{BCR} / \mathrm{ABL}$ represents an alternative approach to treat CML. For example, arsenic was shown to induce ubiquitination and degradation of BCR/ABL via upregualtion of c-CBL, a RING-type E3 ligase [37]. In addition, the small molecular 
deubiquitinase inhibitor WP1130 and histone deacetylase inhibitor LAQ824 were also found to induce BCR/ABL ubiquitination, which results in a reduction in $\mathrm{BCR} / \mathrm{ABL}$ signaling and promotes CML cell apoptosis [38, 39]. In this study, we observed that JNJ-165 decreased mRNA of BCR/ABL. However, our data did not support that JNJ-165 is a transcription inhibitor, because JNJ-165 treatment fail to affect the BCR/ABL promoter. Additionally, JNJ-165mediated down-regulation of BCR/ABL was independent of caspase activation. Based on these, we investigated whether $\mathrm{BCR} / \mathrm{ABL}$ protein degradation was pathways for JNJ-165 actions, and found that cotreatment with MG-132 reversed the JNJ-165-mediated inhibition of the $\mathrm{BCR} / \mathrm{ABL}$ protein. Furthermore, we demonstrated that JNJ-165 treatment led to a marked accumulation of polyubiquitinated c-Abl. Western blotting analysis showed a significant increase of PP2A and SHP-1 protein levels in cells treated with JNJ-165, as compared with the untreated control. The serine/threonine phosphatase 2A (PP2A) functions as a tumor suppression by activating protein tyrosine phosphates 1 (SHP-1), which catalyzes BCR/ ABL dephosphorylation and proteosomal degradation [35]. However, the PP2A protein is usually inactivated in CML cells because BCR/ABL stimulates prevention of its auto-dephosphorylation at tyrosine 307 [35, 40] and cancerous inhibitor of PP2A (CIP2A) that has been shown to be overexpressed in CML patients destined to progress to blast crisis mediates inhibition of PP2A [41]. Neviani

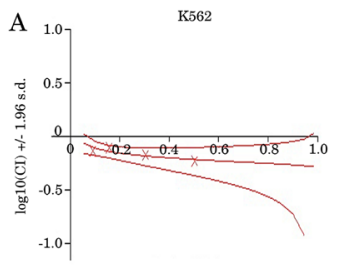

C

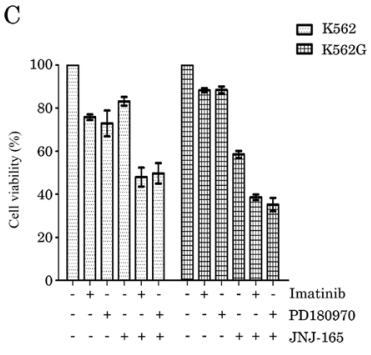

E

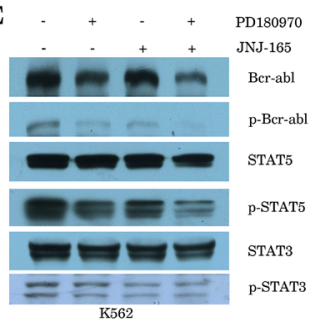

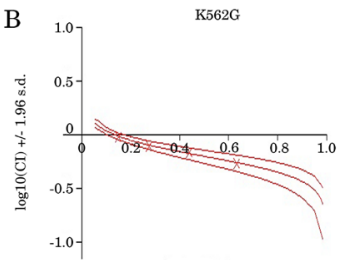

$\mathrm{D}$

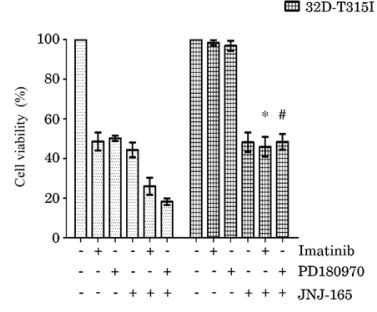

$\mathrm{F}$

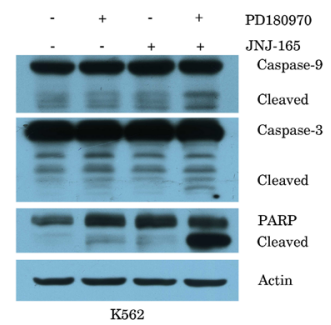

G
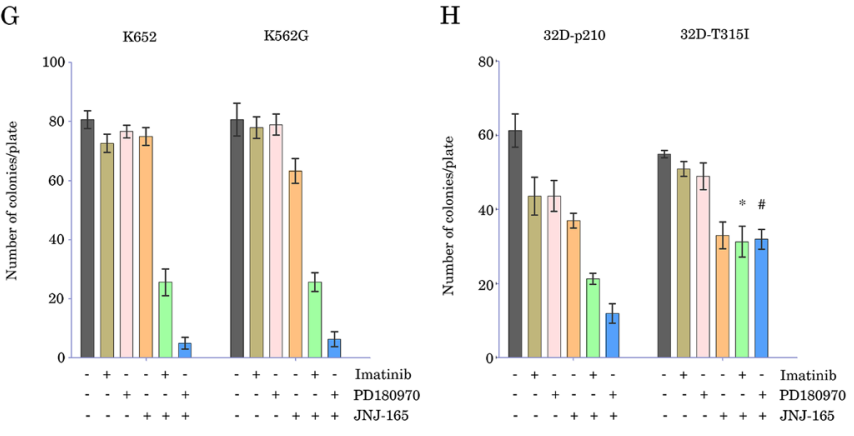

I

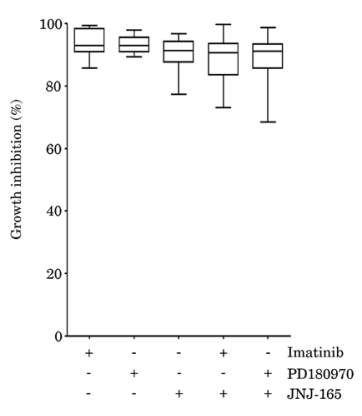

J

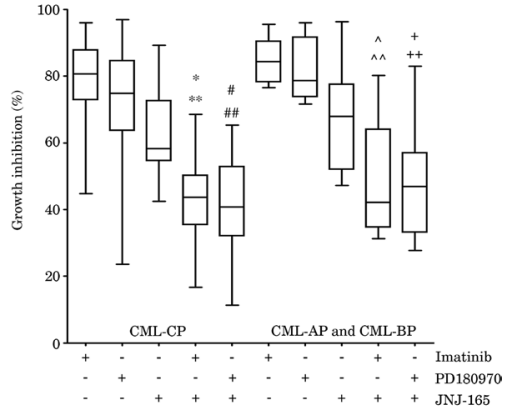

Figure 5: Enhanced suppression of CML cell lines and primary cells proliferation using the combination of JNJ-165 and Imatinib or PD180970. (A) and (B) K562 and K562/G cells were treated with a series of doses of JNJ-165 and PD180970 for $48 \mathrm{~h}$. Growth inhibition was assessed by a MTT assay. The combination index (CIN) was calculated by Calcusyn software and expressed as $\log 10(\mathrm{CIN})$. Where calculable, $95 \%$ confidence intervals are shown. The results were calculated from three independent experiments. (C) and (D) CML cell lines (Figure 5C for K562 and K562/G, 5D for 32D-BCR/ABL and 32D-BCR/ABL-T315I) were treated with JNJ-165 (2 $\mu \mathrm{M})$, Imatinib (50 nM), PD180970 (50 nM), and JNJ-165-Imatinib, JNJ-165-PD180970 combination for $48 \mathrm{~h}$. Cell viability was determined by a MTT assay. Mean \pm SD. $n=3$ independent experiments. ${ }^{*} P>0.05,{ }^{*} P>0.05$. (E) and (F) K562 cells were treated with JNJ-165 (2 $\mu \mathrm{M})$, PD180970 (50nM), and JNJ-165-PD180970 combination for $48 \mathrm{~h}$. Whole-cell lysates were subjected to Western blotting analysis to examine the protein levels of total BCR/ABL, p-BCR-ABL (Tyr177), total Stat5, p-Stat5 (Tyr694), total Stat3, p-Stat3 (Ser727), caspase-9, caspase-3 and PARP. Actin was used as a loading control. The results are representatives of three independent experiments. (G) and $(\mathbf{H})$ CML cell lines are treated with JNJ-165 $(0.5 \mu \mathrm{M})$, Imatinib $(12.5 \mathrm{nM})$ or PD180970 (12.5 $\mathrm{nM})$ alone or in combination, and then plated in triplicate, at a density of 2000 cells $/ \mathrm{ml}$ in methylcellulose medium. Colony counts at 7 days are shown as the average of three independent experiments; $\operatorname{Bar} \pm \mathrm{SD}(n=3)$. ${ }^{*} P>0.05,{ }^{*} P>0.05$. (I) and (J) Primary cells from patients with CML (Figure 5I for BCR/ABL negative or close to negative patients, Figure $5 \mathrm{~J}$ for BCR/ABL positive patients) were treated with JNJ-165 (2 $\mu \mathrm{M})$ alone or in combination with TKIs including Imatinib $(50 \mathrm{nM})$ or PD180970 $(50 \mathrm{nM})$ for $72 \mathrm{~h}$, and then cell viability was measured by a MTT assay. *represents $P<0.0001 / P<0.0001$, JNJ-165-Imatinib vs JNJ-165/Imatinib; " ${ }^{*}$ represents $P<0.0001 / P<0.0001$, JNJ-165-PD180970 vs JNJ-165/ PD180970; ^represents $P=0.0407 /<0.0001$, JNJ-165-Imatinib vs JNJ-165/Imatinib; ${ }^{+}$represents $P<0.0001 / P=0.0243$. 
et al., [42] demonstrated that PP2A-activating agents such as FTY720 selectively reduced survival and self-renewal of TKI-resistant CML stem cells, through BCR/ABL kinase-independent pathway. Taken together, our data suggest that activation of SHP-1-PP2A pathway may contribute to the cytotoxic action of JNJ-165. However, further studies are required to elucidate the exact mechanism by JNJ-165 deregulate SHP-1-PP2A pathway.

Combination therapy is necessary for cancer because tumors are genetically diverse and drug-resistant seems inevitable [43]. Having established an effect for JNJ-165 as a single agent in p53 mutant CML cells, we also investigated the possibility of combining JNJ-165 with the TKIs Imatinib or PD180970 that is active against several BCR/ABL mutations [31,32], so as to reinforce their respective antileukemic activities. We showed that JNJ-165 significantly and synergistically increased TKIs oncotoxicity both in CML cell lines with p53 mutant and primary CML cells with $\mathrm{BCR} / \mathrm{ABL}$-positive, while the combination was not significant toxic for MNCs from BCR/ABL-negative CML patient. Notably, this combination markedly enhanced the inhibition of
$\mathrm{BCR} / \mathrm{ABL}$ expression and phosphorylation, indicating a critical role of the $\mathrm{BCR} / \mathrm{ABL}$ signaling in mediating the synergy of JNJ-165 plus TKI. However, in CML cells harboring BCR/ABL-T315I mutation, all combinations of JNJ-165with the TKIs did not increase cell death compared with JNJ-165 alone. These results support the notion that CML cells with T315I mutation are resistant to most of the TKIs, except for ponatinib [44, 45]. Based on these observations, we concluded that the combined treatment with JNJ-165 and a TKI might offer a novel therapeutic strategy not only for p53 wild-type CML patients, but also for the patients with p53 mutation that is detected in about $20 \%$ of patients in blast crisis $[15,16]$.

In conclusion, we have shown that MDM2 inhibitor JNJ-165 induces cell death in a variety of CML cell lines with p53 mutation, including those resistant to Imatinib and harboring T315I mutation. Furthermore, we have identified a novel mechanism of action of JNJ-165. Our results suggest that JNJ-165, used either alone or in combination with TKIs, represents a promising novel targeted approach to overcome TKI resistance and improve patient outcome in CML.
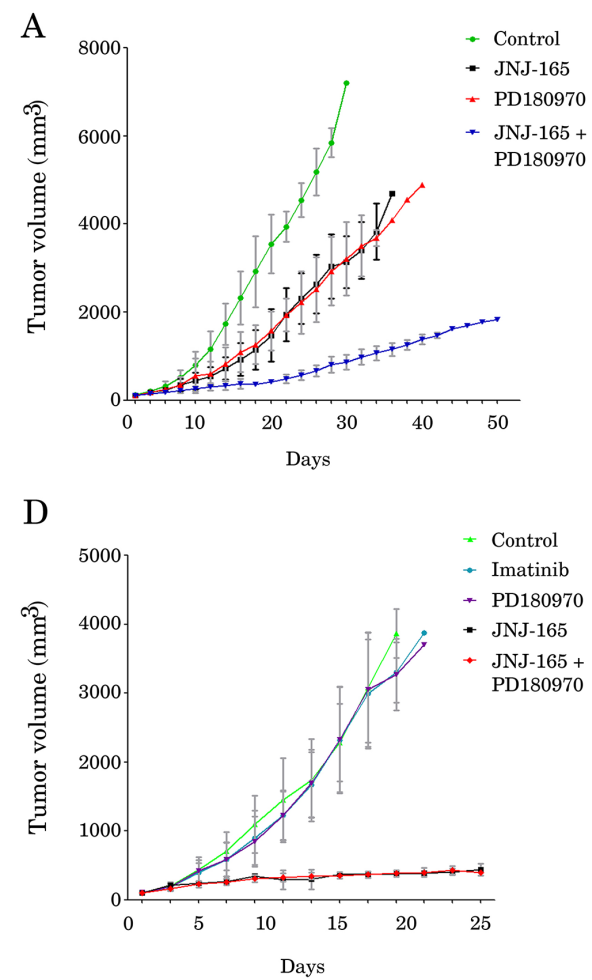

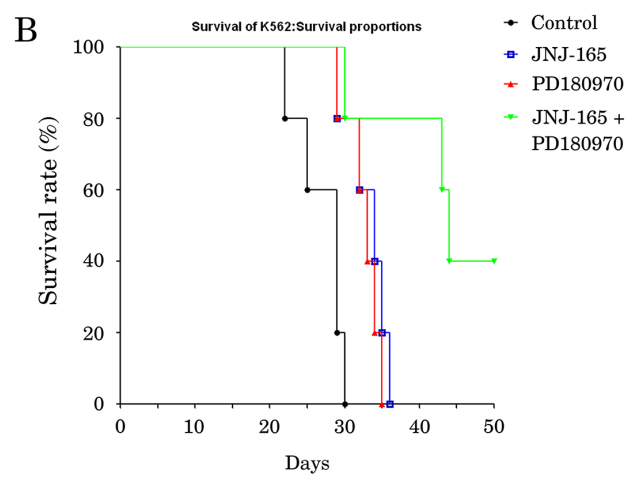

E

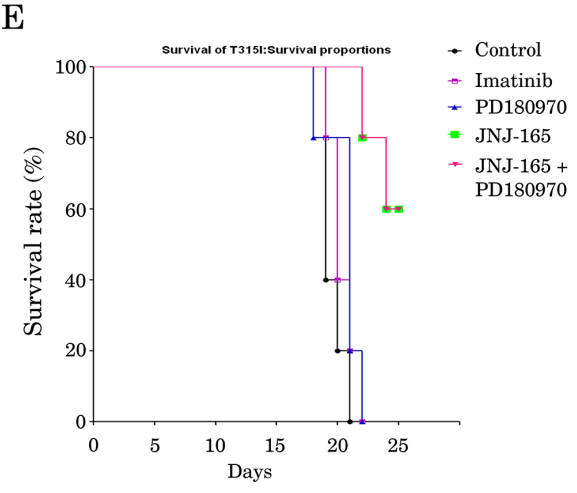

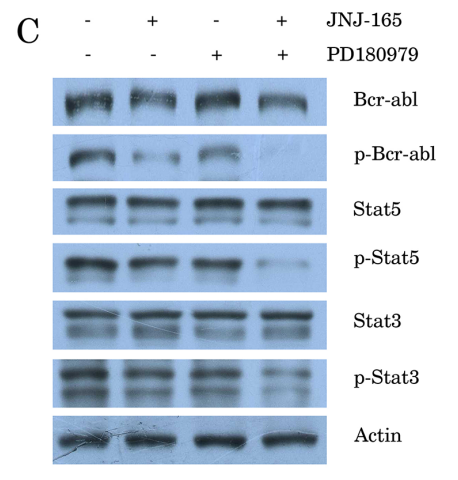

F

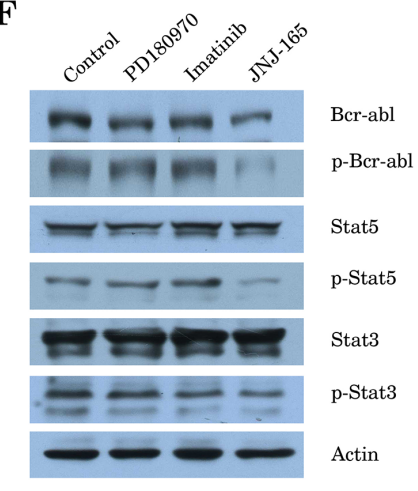

Figure 6: The synergetic lethality of JNJ-165 combined with TKIs in CML cells, but not in T315I cells in vivo. SCID mice bearing subcutaneous K562 xenografts $(n=10)$ were randomized to receive one of the following treatments on 7 consecutive days: PBS, JNJ-165 (40 mg/kg/d), PD180970 (50 mg/kg/d), or JNJ-165 combined with PD180970. Whereas, the animals with 32D-BCR/ABL-T315I xenograft $(n=10)$ were divided into five groups and treated as follows: PBS, JNJ-165 (40 mg/kg/d), Imatinib (50 mg/kg/d), PD180970 $(50 \mathrm{mg} / \mathrm{kg} / \mathrm{d})$, or JNJ-165 combined with PD180970. Tumor size and volume in xenografts were measured and are presented as the mean \pm SD (Figure (6A) for K562, (6D) for 32D-BCR/ABL-T315I). Kaplan-Meier survival curves for mice with K562 xenografts treated with different drugs (Figure (6B) for K562, (6E) for 32D-BCR/ABL-T315I). Tumor tissues were obtained on day 5 after treatment, and the levels of $\mathrm{BCR} / \mathrm{ABL}$ protein, phospho-BCR/ABL and downstream molecules were determined by Western blotting. The expression of actin was used as loading control (Figure (6C) for K562, (6F) for 32D-BCR/ABL-T315I). 


\section{MATERIALS AND METHODS}

\section{Reagents and antibodies}

Imatinib mesylate (STI571), Nutlin-3, MG-132, PFTa, and CHX were purchased from Sigma (St Louis, MO, USA), and JNJ-165 and PD180970 were purchased from Selleckchem (Houston, TX, USA). The caspase general inhibitor z-VAD-fmk and casepase-3 inhibitor z-DEVDfmk were obtained from Biovision (Mountain View, CA, USA). All primary antibodies used in this study were purchased from Cell signaling Technology (Beverly, MA, USA), except for the human anti-p53 (ab32380; Epitomics, Burlingame, CA, USA), anti-phospho-p53 (Epitomics), lamin B (Proteintech Group, Chicago, IL, USA), anti-Abl and actin (Santa Cruz, Santa Cruz, CA, USA).

\section{Patient samples and cell lines}

Heparinized bone marrow samples from the patients with CML were obtained after informed consent and with the approval of the Ethics Committee of Zhejiang University the First Affiliated Hospital (Hangzhou, China). The main clinical data of the patients were abstracted from clinical records (Supplementary Table 1). Bone marrow mononuclear cells (MNCs) were isolated by gradient centrifugation with lymphocyte cell separation medium. Human CML cell line K562 was obtained from American Type Culture Collection (ATCC, Rockville, USA). $\mathrm{K} 562 / \mathrm{G}$, an Imatinib-resistant cell line, was kindly provided by Institute of Hematology, Chinese Academy of Medical Sciences (Tianjin, China) [46]. 32D-BCR/ABL, an Imatinib-sensitive murine CML cell line carrying a WT ABL gene, and 32D-BCR/ABL-T315I, an Imatinibresistant CML cell line carrying a T315I mutation in BCR/ ABL were provided by Prof. L Qiu, (Harbin Institute of Hematology \& Oncology, Harbin, China) [47]. DNA was extracted from all cell lines tested for genomic sequence analysis of p53 mutation [48]. Cells were cultured in RPMI 1640 with $10 \%$ fetal bovine serum (FBS, Hyclone, Utah, USA) at $37^{\circ} \mathrm{C}$ and $5 \% \mathrm{CO}_{2}$ as described [49].

\section{Cell viability}

For cell proliferation assays, leukemia cells were seeded into 96 -well plates at a density of $15 \times 10^{4}$ cells/ $\mathrm{ml}$ and then treated with different agents at the indicated doses in the figure legends. After a 48-hour or 72-hour incubation period, $20 \mu \mathrm{l}$ of 3-(4,5-dimethylthiazol-2-yl) -2,5-diphenyltetrazolium bromide (MTT; Sigma) solution $(5 \mathrm{mg} / \mathrm{ml})$ was added into each well and cells were cultured for an additional 4 hours at $37^{\circ} \mathrm{C}$, then the supernatants were removed and $200 \mu \mathrm{l}$ DMSO (Sigma) was used to dissolve the formazan crystals. Absorbance was read at $570 \mathrm{~nm}$ with a microplate reader (Bio-RAD,
Berkeley, USA). Each assay was performed three times in triplicate.

\section{Leukemic colony-forming cell assay}

AML cells were cultured in $0.8 \%$ methylcellulose as described previously [49]. Briefly, $2 \times 10^{3}$ cells were placed in 35-mm tissue culture dishes containing Iscove's modified Dulbecco's (IMDM) medium supplemented with 20\% FBS (Hyclone), $100 \mu \mathrm{M}$ ß-mercaptoethanol, and methylcellulose at final concentration of $0.8 \%$. After 10 to 12 days incubation at $37^{\circ} \mathrm{C}$ the number of colonies containing more than 20 cells was counted under an inverted microscope (Olympus).

\section{Assessment of apoptosis}

Detection of apoptosis was performed by mean of the annexin V-FITC and propidium iodide (PI) detection kit (BD Pharmingen, San Diego, CA, USA). Briefly, K562 and $\mathrm{K} 562 \mathrm{G}$ cells were treated with JNJ-165 $(2 \mu \mathrm{M})$ for 48 hours, washed with PBS buffer containing $5 \mathrm{mmol} / \mathrm{L}$ EDTA, incubated in the dark at $4^{\circ} \mathrm{C}$ with annexin V-FITC and PI for $30 \mathrm{~min}$, and then analyzed with FACScan flow cytometer and CELL Quest software (Becton Dickinson, Franklin Lakes, USA).

\section{Western blot analysis}

After treatment, cytoplasmic and nuclear extracts were prepared using Nuclear/Cytosol Fractionation Kit (BioVision) according to the manufacturer's manual, and fifty $\mu \mathrm{g}$ samples of nuclear, cytoplasmic, or whole cell extracts were subjected to Western blotting as previously described [49].

\section{Immunoprecipitation of Bcr-Abl and immunoblot analysis}

Following the treatment with JNJ-165, cells were lysed in lysis buffer for $30 \mathrm{~min}$ on ice, and the nuclear and cellular debris were cleared by centrifugation. Cell lysates $(100 \mu \mathrm{g})$ were incubated with Abl-specific monoclonal antibody for $1 \mathrm{~h}$ at $4^{\circ} \mathrm{C}$. To this mixture, washed protein G-agarose beads were added and incubated overnight at $4^{\circ} \mathrm{C}$. The immunoprecipitates were washed three times in the lysis buffer, and proteins were eluted with the SDS sample loading buffer prior to immunoblot analyses with specific antibodies against anti-ubiquitin antibody (Santa Cruz).

\section{BCR promoter luciferase reporter assay}

Luciferase report vector of BCR promoter was constructed using pGL-2-basic vector as following: BCR promoter fragment $(-816$ to +71$)$ was amplified by PCR 
using genomic DNA extracted from K562 cells, which contain the Philadelphia chromosome, with forward primer 5'-ATCTCGAGCTTGGGGACACGCGGCTGGA-3' and reverse primer 5'-ATAAGCTTCATGCGCGGGGCTCT GAGT-3', designed to include an Xho I site and a Hind III site, respectively. The PCR product was cloned into pGL2basic vector (Promega, Madison, WI, USA), and the DNA sequence was confirmed using a 3730 DNA Analyzer (ABI, Applied Biosystems, Foster City, CA, USA). To test whether JNJ-165 affect the activity of BCR promoter, 293T cells were transfected with BCR promoter-luciferase report plasmid for 24 hours, and then treated with $2 \mu \mathrm{M}$ JNJ-165 for the indicated times. After treatment with JNJ-165, cell lysates were analyzed for luciferase activity using the Luciferase Assay System Kit (Promega).

\section{Reverse transcription quantitative real-time PCR (RT-qPCR)}

Total cellular RNA was purified using the RNeasy Mini Kit (Qiagen, Valencia, CA, USA). Reverse transcription was performed with random hexamers using Superscript first-strand synthesis system (Invitrogen, Carlsbad, CA, USA) according to the manufacturer's instructions. All PCR reactions were carried out on the iQ5 thermal cycling system (Bio-Rad Laboratories, Hercules, CA, USA). Optimal reaction conditions for amplification of both BCR/ABL and $\beta$-actin were as follows: $30 \mathrm{sec}$ at $95^{\circ} \mathrm{C}$ for initial denaturing, $10 \mathrm{sec}$ at $95^{\circ} \mathrm{C}$ for denaturing and $60 \mathrm{sec}$ at $60^{\circ} \mathrm{C}$ for annealing and extension for a total of 40 cycles. The PCR primers were as follows: BCR/ABLsense: 5'-TCCGCTGACCATCAAYAAGGA-3'; antisense: 5'-CACTCAGACCCTGAGGCTCAA-3'; $\beta$-actin -sense: 5'-GTCATCACCATTGGCAATGAG-3'; antisense: 5'CGTCACACTTCATGATGGAGTT - $3^{\prime}$. Fluorescence data from each sample were analyzed with the $2^{-\Delta \Delta \mathrm{Ct}}$ method as described in detail elsewhere [49].

\section{Immunofluorescence assay}

The p53 protein localization was examined by Immunofluorescence assay. K562 cells were treated with PBS or with JNJ-165 (1 $\mu \mathrm{M})$ for 48 hours, washed in PBS, then fixed in 4\% paraformaldehyde, blocked with PBS containing $2 \%$ goat serum, and $0.2 \%$ Triton X-100. After removing the blocking buffer, cells were incubated with anti- human p53 primary antibody overnight. Primary antibody was detected by Texas Green-conjugated goat anti-rabbit antibody (Santa Cruz). Cells were counterstained with DAPI (Southern Biotech, Birmingham, AL, USA).

\section{In vivo tumor xenograft study}

Sever combined immunodeficient (SCID) mice were obtained from the Shanghai Experimental Animal center of the Chinese Academy of Sciences (Shanghai, China). Human K562 cells or 32D-BCR/ABL-T315I cells were subcutaneously injected into right flank of each mouse, respectively. When tumor's volume reached $100-120 \mathrm{~mm}^{3}$, the animals were randomized into treatment groups. Tumor growth was monitored and measured as described previously [50]. For K562 xenografts, the mice were divided into four groups and treated as follows: PBS, JNJ-165 (40 mg/kg/d), PD180970 (50 mg/kg/d), or JNJ-165 combined with PD180970. Whereas, the animals with 32D-BCR/ABL-T315I xenograft were divided into five groups and treated as follows: PBS, JNJ-165 (40 mg/kg/d), Imatinib (50 mg/kg/d), PD180970 (50 mg/kg/d), or JNJ-165 combined with PD180970. The agents used in this study were administered by gavage for seven consecutive daily, and dosages were obtained from previously reported studies [24, 50]. Tumor specimens from one of each groups were harvested at five days after treatment, and then were analyzed by Western blotting for the expression of BCR/ABL, STAT3 and STAT5.

\section{Statistical analysis}

All experiments were performed in triplicates, and the results were presented as means $\pm \mathrm{SD}$. Data were statistically evaluated by ANOVA and Tukey's test using Prism version 2.0 software (GraphPad Software, San Diego, CA, USA). Synergisms in the combination treatments were analyzed using a commercially available software program (CalcuSyn, Biosoft, Cambridge, UK). A $P$-value of $<0.05$ was considered significant.

\section{ACKNOWLEDGMENTS}

This work was supported by National Natural Science Foundation of China grants (No 81370645, 81500110,81200384 and 81372256), Doctoral Fund of Ministry of Education of China (No 20120101110010), and Funds of Health and Family Planning Commission of Zhejiang Province (no. 2014RCA006). Funds of Health and Family Planning Commission of Zhejiang Province (No. 2014RCA006).

\section{CONFLICTS OF INTEREST}

None.

\section{Authors' contribution}

WQ contributed to the conception and design of this study; WQ and LY performed the statistical analysis and wrote the manuscript; LY, HL, JH, WX, JW and YX carried out experimental studies; all authors read and approved the final manuscript. 


\section{Authors' information}

LY holds an MSc degree in Medicine and is $\mathrm{PhD}$ student in Medicine. HL, JH, WX, XY and XY have a PhD degree in Medicine. JW holds an MSc degree in Medicine. WQ is a professor in the Department of Hematology.

\section{REFERENCES}

1. Druker BJ. Translation of the Philadelphia chromosome into therapy for CML. Blood. 2008; 112:4808-4817.

2. Kantarjian H, Shah NP, Hochhaus A, Cortes J, Shah S, Ayala M, Moiraghi B, Shen Z, Mayer J, Pasquini R, Nakamae H, Huguet F, Boqué C, et al. Dasatinib versus imatinib in newly diagnosed chronic-phase chronic myeloid leukemia. N Engl J Med. 2010; 362:2260-2270.

3. Saglio G, Kim DW, Issaragrisil S, le Coutre P, Etienne G, Lobo C, Pasquini R, Clark RE, Hochhaus A, Hughes TP, Gallagher N, Hoenekopp A, Dong M, et al. ENESTnd Investigators. Nilotinib versus imatinib for newly diagnosed chronic myeloid leukemia. N Engl J Med. 2010; 362:2251-2259.

4. Deininger M, Buchdunger E, Druker BJ. The development of imatinib as a therapeutic agent for chronic myeloid leukemia. Blood. 2005; 105:2640-2653.

5. Druker BJ, Guilhot F, O’Brien SG, Gathmann I, Kantarjian H, Gattermann N, Deininger MW, Silver RT, Goldman JM, Stone RM, Cervantes F, Hochhaus A, Powell BL, et al. IRIS Investigators. Five-year follow-up of patients receiving imatinib for chronic myeloid leukemia. N Engl J Med. 2006; $355: 2408-2417$

6. Gorre ME, Mohammed M, Ellwood K, Hsu N, Paquette R, Rao PN, Sawyers CL. Clinical resistance to STI-571 cancer therapy caused by BCR-ABL gene mutation or amplification. Science. 2001; 293:876-880.

7. Koptyra M, Falinski R, Nowicki MO, Stoklosa T, Majsterek I, Nieborowska-Skorska M, Blasiak J, Skorski T. BCR/ABL kinase induces self-mutagenesis via reactive oxygen species to encode imatinib resistance. Blood. 2006; 108:319-3127.

8. de Lavallade H, Apperley JF, Khorashad JS, Milojkovic D, Reid AG, Bua M, Szydlo R, Olavarria E, Kaeda J, Goldman JM, Marin D. Imatinib for newly diagnosed patients with chronic myeloid leukemia: incidence of sustained responses in an intention-to-treat analysis. J Clin Oncol. 2008; 26:3358-3363.

9. Soverini S, Rosti G, Iacobucci I, Baccarani M, Martinelli G. Choosing the best second-line tyrosine kinase inhibitor in imatinib-resistant chronic myeloid leukemia patients harboring Bcr-Abl kinase domain mutations: how reliable is the $\mathrm{IC}_{50}$ ?. Oncologist. 2011; 16:868-876.

10. Graham SM, Jørgensen HG, Allan E, Pearson C, Alcorn MJ, Richmond L, Holyoake TL. Primitive, quiescent, Philadelphiapositive stem cells from patients with chronic myeloid leukemia are insensitive to STI571 in vitro. Blood. 2002; 99:319-325.
11. Jørgensen HG, Allan EK, Jordanides NE, Mountford JC, Holyoake TL. Nilotinib exerts equipotent antiproliferative effects to imatinib and does not induce apoptosis in CD34+ CML cells. Blood. 2007; 109:4016-4019.

12. Konig H, Copland M, Chu S, Jove R, Holyoake TL, Bhatia R. Effects of dasatinib on SRC kinase activity and downstream intracellular signaling in primitive chronic myelogenous leukemia hematopoietic cells. Cancer Res. 2008; 68:9624-9633.

13. Wendel HG, de Stanchina E, Cepero E, Ray S, Emig M, Fridman JS, Veach DR, Bornmann WG, Clarkson B, McCombie WR, Kogan SC, Hochhaus A, Lowe SW. Loss of p53 impedes the antileukemic response to BCR-ABL inhibition. Proc Natl Acad Sci USA. 2006; 103:7444-7449.

14. Cheok CF, Verma CS, Baselga J, Lane DP. Translating p53 into the clinic. Nat Rev Clin Oncol. 2011; 8:25-37.

15. Feinstein E, Cimino G, Gale RP, Alimena G, Berthier R, Kishi K, Goldman J, Zaccaria A, Berrebi A, Canaani E. p53 in chronic myelogenous leukemia in acute phase. Proc Natl Acad Sci USA. 1991; 88:6293-6297.

16. Mashal R, Shtalrid M, Talpaz M, Kantarjian H, Smith L, Beran M, Cork A, Trujillo J, Gutterman J, Deisseroth A. Rearrangement and expression of $\mathrm{p} 53$ in the chronic phase and blast crisis of chronic myelogenous leukemia. Blood. 1990; 75:180-189.

17. Trotta R, Vignudelli T, Candini O, Intine RV, Pecorari L, Guerzoni C, Santilli G, Byrom MW, Goldoni S, Ford LP, Caligiuri MA, Maraia RJ, Perrotti D, et al. BCR/ABL activates mdm2 mRNA translation via the La antigen. Cancer Cell. 2003; 3:145-160.

18. Kurosu T, Wu N, Oshikawa G, Kagechika H, Miura O. Enhancement of imatinib-induced apoptosis of BCR/ABLexpressing cells by nutlin-3 through synergistic activation of the mitochondrial apoptotic pathway. Apoptosis. 2010; 15:608-620.

19. Peterson LF, Mitrikeska E, Giannola D, Lui Y, Sun H, Bixby D, Malek SN, Donato NJ, Wang S, Talpaz M. p53 stabilization induces apoptosis in chronic myeloid leukemia blast crisis cells. Leukemia. 2011; 25:761-769.

20. Kojima K, Burks JK, Arts J, Andreeff M. The novel tryptamine derivative JNJ-26854165 induces wild-type p53- and E2F1-mediated apoptosis in acute myeloid and lymphoid leukemias. Mol Cancer Ther. 2010; 9:2545-2557.

21. Yuan Y, Liao YM, Hsueh CT, Mirshahidi HR. Novel targeted therapeutics: inhibitors of MDM2, ALK and PARP. J Hematol Oncol. 2011; 4:16.

22. Tabernero J, Dirix L, Schöffski P, Cervantes A, LopezMartin JA, Capdevila J, van Beijsterveldt L, Platero S, Hall B, Yuan Z, Knoblauch R, Zhuang SH. A phase I firstin-human pharmacokinetic and pharmacodynamic study of serdemetan in patients with advanced solid tumors. Clin Cancer Res. 2011; 17:6313-6321. 
23. Lehman JA, Hauck PM, Gendron JM, Batuello CN, Eitel JA, Albig A, Kadakia MP, Mayo LD. Serdemetan antagonizes the Mdm2-HIF1 $\alpha$ axis leading to decreased levels of glycolytic enzymes. PLoS One. 2013; 8:e74741.

24. Smith MA, Gorlick R, Kolb EA, Lock R, Carol H, Maris JM, Keir ST, Morton CL, Reynolds CP, Kang MH, Arts J, Bashir T, Janicot M, et al. Initial testing of JNJ26854165 (Serdemetan) by the pediatric preclinical testing program. Pediatr Blood Cancer. 2012; 59:329-332.

25. Komarov PG, Komarova EA, Kondratov RV, ChristovTselkov K, Coon JS, Chernov MV, Gudkov AV. A chemical inhibitor of p53 that protects mice from the side effects of cancer therapy. Science. 1999;285:1733-1737.

26. Vassilev LT, Vu BT, Graves B, Carvajal D, Podlaski F, Filipovic Z, Kong N, Kammlott U, Lukacs C, Klein C, Fotouhi N, Liu EA. In vivo activation of the $\mathrm{p} 53$ pathway by small-molecule antagonists of MDM2. Science. 2004;303:844-848.

27. Warsch W, Grundschober E, Berger A, Gille L, CernyReiterer S, Tigan AS, Hoelbl-Kovacic A, Valent P, Moriggl R, Sexl V. STAT5 triggers BCR-ABL1 mutation by mediating ROS production in chronic myeloid leukaemia. Oncotarget. 2012; 3:1669-1687. doi: 10.18632/oncotarget.806.

28. Spiekermann K, Pau M, Schwab R, Schmieja K, Franzrahe S, Hiddemann W. Constitutive activation of STAT3 and STAT5 is induced by leukemic fusion proteins with protein tyrosine kinase activity and is sufficient for transformation of hematopoietic precursor cells. Exp Hematol. 2002; 30:262-271.

29. Chan WW, Wise SC, Kaufman MD, Ahn YM, Ensinger CL, Haack T, Hood MM, Jones J, Lord JW, Lu WP, Miller D, Patt WC, Smith BD, et al. Conformational control inhibition of the BCR-ABL1 tyrosine kinase, including the gatekeeper T315I mutant, by the switch-control inhibitor DCC-2036. Cancer Cell. 2011; 19:556-568.

30. Chomel JC, Turhan AG. Chronic myeloid leukemia stem cells in the era of targeted therapies: resistance, persistence and long-term dormancy. Oncotarget. 2011; 2:713-727. doi: 10.18632/oncotarget.333.

31. Dorsey JF, Jove R, Kraker AJ, Wu J. The pyrido[2,3-d] pyrimidine derivative PD180970 inhibits p210 Bcr-Abl tyrosine kinase and induces apoptosis of K562 leukemic cells. Cancer Res. 2000; 60:3127-3131.

32. La Rosée P, Corbin AS, Stoffregen EP, Deininger MW, Druker BJ. Activity of the Bcr-Abl kinase inhibitor PD180970 against clinically relevant Bcr-Abl isoforms that cause resistance to imatinib mesylate (Gleevec, STI571). Cancer Res. 2002; 62:7149-7153.

33. Shi X, Jin Y, Cheng C, Zhang H, Zou W, Zheng Q, Lu Z, Chen Q, Lai Y, Pan J. Triptolide inhibits Bcr-Abl transcription and induces apoptosis in STI571-resistant chronic myelogenous leukemia cells harboring T315I mutation. Clin Cancer Res. 2009; 15:1686-1697.

34. Quintás-Cardama A, Cortes J. Molecular biology of bcrabl1-positive chronic myeloid leukemia. Blood. 2009; 113:1619-1630.
35. Neviani P, Santhanam R, Trotta R, Notari M, Blaser BW, Liu S, Mao H, Chang JS, Galietta A, Uttam A, Roy DC, Valtieri M, Bruner-Klisovic R, et al. The tumor suppressor PP2A is functionally inactivated in blast crisis CML through the inhibitory activity of the BCR/ABL-regulated SET protein. Cancer Cell. 2005; 8:355-368.

36. Wade M, Li YC, Wahl GM. MDM2, MDMX and p53 in oncogenesis and cancer therapy. Nat Rev Cancer. 2013; 13:83-96.

37. Mao JH, Sun XY, Liu JX, Zhang QY, Liu P, Huang QH, Li KK, Chen Q, Chen Z, Chen SJ. As4S4 targets RINGtype $\mathrm{E} 3$ ligase c-CBL to induce degradation of BCR-ABL in chronic myelogenous leukemia. Proc Natl Acad Sci USA. 2010; 107:21683-21688.

38. Sun H, Kapuria V, Peterson LF, Fang D, Bornmann WG, Bartholomeusz G, Talpaz M, Donato NJ. Bcr-Abl ubiquitination and Usp9x inhibition block kinase signaling and promote CML cell apoptosis. Blood. 2011; 117:3151-3162.

39. Nimmanapalli R, Fuino L, Bali P, Gasparetto M, Glozak M, Tao J, Moscinski L, Smith C, Wu J, Jove R, Atadja P, Bhalla K. Histone deacetylase inhibitor LAQ824 both lowers expression and promotes proteasomal degradation of Bcr-Abland induces apoptosis of imatinib mesylatesensitive or -refractory chronic myelogenous leukemia-blast crisis cells. Cancer Res. 2003; 63:5126-5135.

40. Perrotti D, Neviani P. ReSETting PP2A tumour suppressor activity in blast crisis and imatinib-resistant chronic myelogenous leukaemia. Br J Cancer. 2006; 95:775-781.

41. Lucas CM, Harris RJ, Giannoudis A, Copland M, Slupsky JR, Clark RE. Cancerous inhibitor of PP2A (CIP2A) at diagnosis of chronic myeloid leukemia is a critical determinant of disease progression. Blood. 2011; 117:6660-6668.

42. Neviani P, Harb JG, Oaks JJ, Santhanam R, Walker CJ, Ellis JJ, Ferenchak G, Dorrance AM, Paisie CA, Eiring AM, Ma Y, Mao HC, Zhang B, et al. PP2A-activating drugs selectively eradicate TKI-resistant chronic myeloid leukemic stem cells. J Clin Invest. 2013; 123:4144-4157.

43. Levinson AD. Cancer therapy reform. Science. 2010; 328:137.

44. Cortes JE, Kim DW, Pinilla-Ibarz J, le Coutre P, Paquette R, Chuah C, Nicolini FE, Apperley JF, Khoury HJ, Talpaz M, DiPersio J, DeAngelo DJ, Abruzzese E, et al. PACE Investigators. A phase 2 trial of ponatinib in Philadelphia chromosome-positive leukemias. N Engl J Med. 2013; 369:1783-1796.

45. Cassuto O, Dufies M, Jacquel A, Robert G, Ginet C, Dubois A, Hamouda A, Puissant A, Luciano F, Karsenti JM, Legros L, Cassuto JP, Lenain P, et al. All tyrosine kinase inhibitor-resistant chronic myelogenous cells are highly sensitive to ponatinib. Oncotarget. 2012; 3:1557-1565. doi: 10.18632/oncotarget.692.

46. Tong Y, Liu YY, You LS, Qian WB. Perifosine induces protective autophagy and upregulation of ATG5 in human chronic myelogenous leukemia cells in vitro. Acta Pharmacol Sin. 2012; 33:542-550. 
47. Lu Z, Jin Y, Qiu L, Lai Y, Pan J. Celastrol, a novel HSP90 inhibitor, depletes Bcr-Abl and induces apoptosis in imatinib-resistant chronic myelogenous leukemia cells harboring T315I mutation. Cancer Lett. 2010; 290:182-191.

48. Feinstein E, Cimino G, Gale RP, Alimena G, Berthier R, Kishi K, Goldman J, Zaccaria A, Berrebi A, Canaani E. p53 in chronic myelogenous leukemia in acute phase. Proc Natl Acad Sci USA. 1991; 88:6293-6297.
49. Meng H, Jin Y, Liu H, You L, Yang C, Yang X, Qian W. SNS-032 inhibits mTORC1/mTORC2 activity in acute myeloid leukemia cells and has synergistic activity with perifosine against Akt. J Hematol Oncol. 2013; 6:18.

50. Zhang L, Insel PA. The pro-apoptotic protein Bim is a convergence point for $\mathrm{cAMP} /$ protein kinase A- and glucocorticoid-promoted apoptosis of lymphoid cells. J Biol Chem. 2004; 279:20858-20865. 